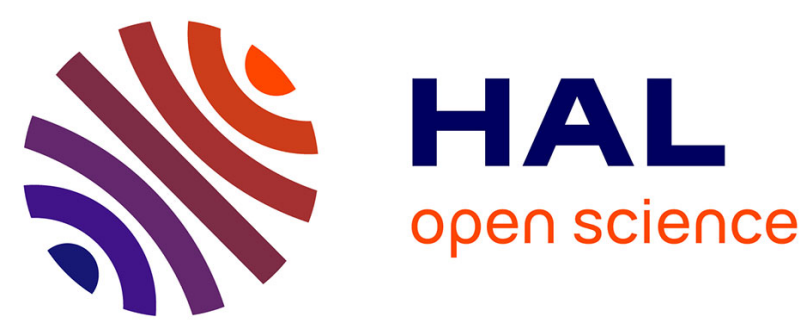

\title{
Straightforward access to densely substituted chiral succinimides through enantioselective organocatalyzed Michael addition of $\alpha$-alkyl-cyclic ketones to maleimides
} Lai Wei, Li Chen, Franck Le Bideau, Pascal Retailleau, Françoise Dumas

\section{- To cite this version:}

Lai Wei, Li Chen, Franck Le Bideau, Pascal Retailleau, Françoise Dumas. Straightforward access to densely substituted chiral succinimides through enantioselective organocatalyzed Michael addition of $\alpha$-alkyl-cyclic ketones to maleimides. Organic Chemistry Frontiers, 2020, 7 (10), pp.1224-1229. 10.1039/C9QO01463B . hal-03009508

\author{
HAL Id: hal-03009508 \\ https://hal.science/hal-03009508
}

Submitted on 17 Nov 2020

HAL is a multi-disciplinary open access archive for the deposit and dissemination of scientific research documents, whether they are published or not. The documents may come from teaching and research institutions in France or abroad, or from public or private research centers.
L'archive ouverte pluridisciplinaire $\mathbf{H A L}$, est destinée au dépôt et à la diffusion de documents scientifiques de niveau recherche, publiés ou non, émanant des établissements d'enseignement et de recherche français ou étrangers, des laboratoires publics ou privés. 


\section{Straightforward Access to Densely Substituted Chiral Succinimides through Enantioselective Organocatalyzed Michael Addition of $\alpha$ - Alkyl-Cyclic Ketones to Maleimides}

Received 00th January 20xx Accepted 00th January 20xx

DOI: $10.1039 / x 0 \times x 00000 x$

\author{
Lai Wei, $\dagger^{\mathrm{a}}$ Li Chen, ${ }^{\text {ta }}{ }^{\mathrm{F}}$ Franck Le Bideau, ${ }^{* a}$ Pascal Retailleau, ${ }^{\mathrm{b}}$ and Françoise Dumas*a
}

\begin{abstract}
A simple organocatalytic system provides efficient access to a series of densely substituted chiral succinimides bearing a quaternarytertiary carbon stereocenter sequence in good yields, high diastereo- and enantioselectivities through enantioselective conjugate addition of unreactive $\alpha$-alkyl cyclic ketones to maleimides under microwave-assisted conditions.
\end{abstract}

\section{Introduction}

Owing to their highly congested nature, molecules incorporating stereocontrolled quaternary carbon centers (QCCs) are still the subject of methodological studies, ${ }^{1}$ with the aim of opening new routes towards natural products and biologically active compounds. ${ }^{2}$ For such purpose, conjugate addition referred as Michael reaction ${ }^{3}$ is a powerful tool especially when performed under organocatalyzed ${ }^{4}$ conditions. Most reported corresponding studies have been centered to pro-nucleophiles bearing only one nucleophilic site like aldehydes, ${ }^{5}$ cyanoacetates, $^{6}$ or 1,3 -dicarbonyl compounds. ${ }^{7}$ In such a case, creation of the carbon-carbon bond is oriented either by a regio-blocking or a regio-directing group (Scheme 1) and Michael adducts incorporating the desired stereocontrolled QCC are obtained. A totally regioselective Michael reaction of $\alpha$-aryl ketones or $\alpha$-branched $\beta$-carbonyls is usually due to the enhanced acidic character of $\alpha$-branched position, illustrating the role of a regio-directing group in the selectivity of the process. ${ }^{8}$ For unactivated $\alpha$-alkyl ketones, an increasing complexity results from the presence of two pro-nucleophilic $\alpha$ sites and the possible concurrent formation of undesired regioisomers incorporating only tertiary carbon stereocenters (TCCs) (Scheme 1).

Alkylation at the more hindered $\alpha$-position of such $\alpha$-alkyl cycloalkanones was solved at the stoichiometric level by d'Angelo et al. starting from pre-formed imines of the cheap and commercially available 1-phenylethylamine $1 .{ }^{9} \mathrm{~A}$ plethora of nucleophiles and electrophiles, either substituted or not, were prone to successfully underwent this reaction. ${ }^{10} \mathrm{~A}$ catalytic version was disclosed by Carter et al $^{11}$ involving acrylates as

\footnotetext{
a. UMR CNRS 8076 BioCIS, Conception et Synthèse de Molécules d'Intérêt Thérapeutique (COSMIT), CNRS-Université Paris Sud, Université Paris-Saclay, Faculté de Pharmacie, 5, rue J.-B. Clément, F-92296 Châtenay-Malabry, France E-mail: francoise.dumas@u-psud.fr.

b. UPR 2301, Institut de Chimie des Substances Naturelles, CNRS

avenue de la terrasse, Gif sur Yvette F-91198, France.

+ Equal contribution to this study.

Electronic Supplementary Information (ESI) available: [details of any supplementary information available should be included here]. See DOI: 10.1039/x0xx00000x
}

Michael acceptors and a thiourea-based dual organocatalytic pathway promoting enamine/Brønsted acid activations. Kotsuki et al. later reported ${ }^{12}$ the enantioselective Michael addition of $\alpha$-alkyl cyclic ketones to acrylates promoted by (S)-1phenylethylamine $\mathbf{1}$ under high pressure conditions. The formation of small amounts $(<5 \%)$ of undesired tertiary regioisomers (TCCs) was noticed (Scheme 1, a).

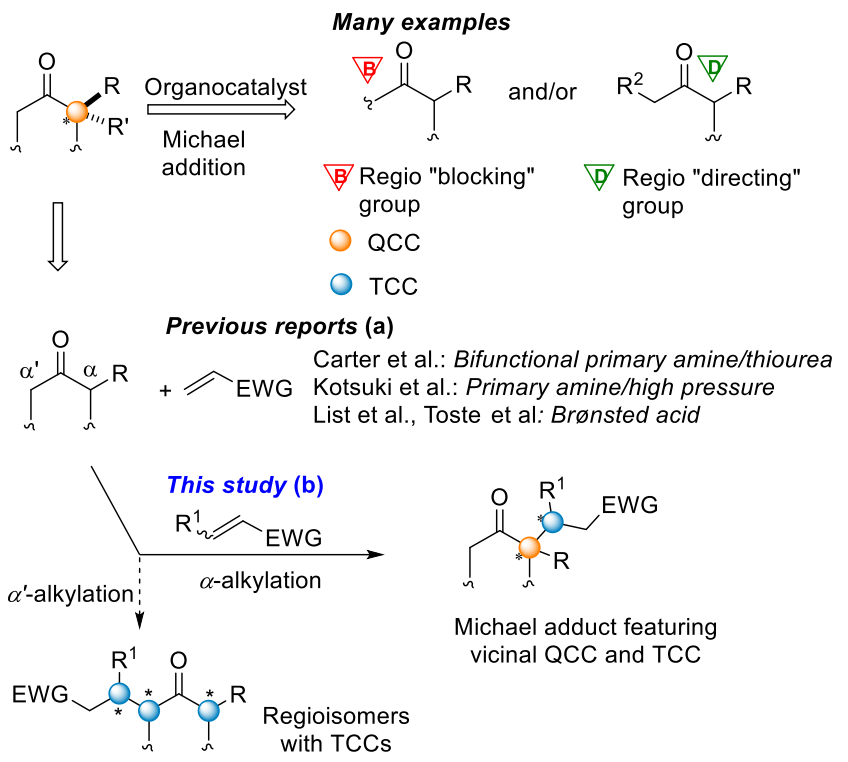

Scheme 1. Organocatalytic strategy to access to densely substituted chiral Michael adducts having vicinal quaternary and tertiary stereogenic centers.

In a complementary approach, List et al. disclosed ${ }^{13}$ the Michael addition of $\alpha$-alkyl cyclanones to $t$-butyl and $i$-propyl vinyl ketones catalyzed by phosphoric acid (S)-TRIP (Scheme 1, a). This enol catalysis based methodology was successfully applied to the synthesis of new Cashmeran odorants designed through molecular modeling. Using the same catalyst, Toste and Yang described a 1,4-addition of $\alpha$-methyl and $n$-butyl cyclohexanones to allenamides as a two-step alternative to the putative Michael addition involving acrolein as electrophile. ${ }^{14}$

\section{Results and discussion}

Despite all these pioneering results (Scheme 1, a) contributing to enrich the access to quaternary carbon stereocenterscontaining molecules, no example of an organocatalyzed Michael reaction leading to the formation of adjacent stereogenic quaternary and tertiary carbon centers (Scheme 1, 
$\left.\mathrm{R}^{1} \neq \mathrm{H}\right)$ starting from unactivated $\alpha$-alkyl cyclic ketones has been reported to date. Recently, a highly regio- and stereoselective Michael addition of stereogenic imine synthesized from allyl cyclopentanone to methyl crotonate and subsequent access to suberosanes, sesquiterpenes of marine origin were reported. ${ }^{15,16}$ Facing an extra steric hindrance generated by 8 substitution in methyl crotonate, in comparison with acrylates or vinyl ketones, this 1,4 -addition required high pressure to cleanly deliver the desired adduct incorporating a sterically crowded vicinal quaternary-tertiary chiral centers motif. ${ }^{10 f}$ Despite extensive trials, we were not able to satisfactorily make this reaction organocatalytic using chiral primary amines bearing (dual activation) or not acidic functions and turned our attention to more reactive Michael acceptors. Thus, reacting $\alpha$ methyl cyclopentanone with acyl phosphonates, $\alpha, 6$ unsaturated keto esters or maleic anhydride in the presence of several primary amines mainly provided degradation products, inseparable mixtures of diastereomers or by-products from catalysts trapping. Maleimides, as prochiral B-substituted Michael acceptors, belong to an important class of compounds that have been successfully used in different asymmetric organocatalytic Michael additions, ${ }^{17}$ providing an easy access to chiral-substituted compounds of interest because of the occurrence of the succinimide moiety in natural products and some clinical drugs. ${ }^{18}$

Herein, we report the first organocatalyzed asymmetric Michael addition of unreactive $\alpha$-alkyl cyclic ketones to maleimides as $B$ substituted electrophile leading to chiral succinimides bearing a quaternary-tertiary carbon stereocenters sequence promoted by primary amines/Brønsted acid co-activation (Figure 1 compounds 1-7/8) under microwave assisted conditions. ${ }^{19}$

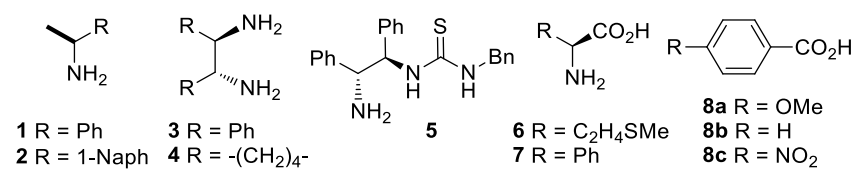

Figure 1. Chiral primary amines 1-7 and co-catalysts 8 used in this study.

Our study was initiated by taking $\alpha$-methylcyclohexanone (9) and methyl maleimide (10b) as starting materials and racemic 1, with or without a carboxylic acid (AcOH or $8 \mathbf{a}-\mathrm{c})$ as organocatalytic system (Table 1). Diastereomers $\mathbf{1 1 b}$ and $\mathbf{1 2 b}$ bearing a quaternary-tertiary carbon stereocenters sequence, their corresponding regioisomers 22 (Scheme 1 and ESI) and aza-Michael adducts $\mathbf{1 3} \mathbf{b}$ were expected as other potential products in this reaction. Without co-catalyst (entry 1 ), only aza-Michael product $\mathbf{1 3 b}$ resulting from the addition of the catalyst 1 on maleimide 10b was generated in $90 \%$ yield in toluene at $80{ }^{\circ} \mathrm{C}$ for $24 \mathrm{~h}$. Acetic acid and $p$-substituted benzoic acids $8 \mathrm{a}-\mathrm{c}$ were then added as co-catalysts improving desired products (11b/12b) yields (entries $2-5$ ) up to $53 \%$ yield with $p$ nitrobenzoic acid $\mathbf{8 c}$ (entry 5). Compound $\mathbf{1 1} \mathbf{b}$ was obtained as the major diastereomer, while $15 \%$ of aza-Michael adducts $\mathbf{1 3 b}$ were isolated as mixtures of diastereomers and 4 to $7 \%$ of regioisomers (see ESI) were detected in the transformation. To our delight, the yield was greatly improved applying microwave $(\mu \mathrm{W})$ irradiation (entry 6 ) delivering in $79 \%$ yield, for $12 \mathrm{~h}$, a mixture of diastereomers $\mathbf{1 1 b}$ and $\mathbf{1 2 b}$ in a good diastereoselectivity $(\mathrm{dr}=82: 18)$.

Table 1. Screening of the reaction conditions.

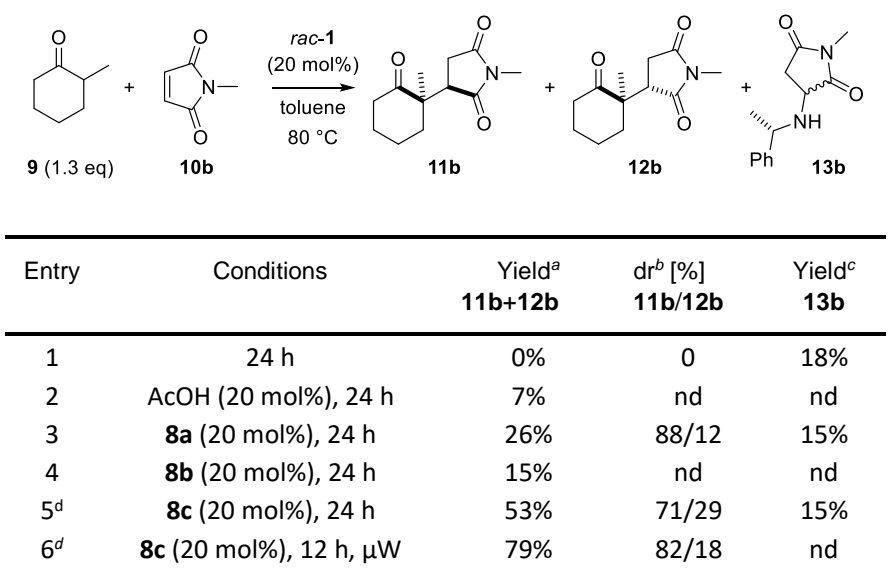

$a$ Combined yields of $\mathbf{1 1 b}$ and $\mathbf{1 2 b}$ isolated by flash chromatography. $b$ Determined by ${ }^{1} \mathrm{H}$ NMR. ${ }^{c}$ Combined yields of aza-Michael adducts isolated by flash chromatography. ${ }^{d} 4-7 \%$ of side regioisomer (Scheme 1 ) was detected by ${ }^{1} \mathrm{H}$ NMR of the crude.

We next evaluated a series of amines 1-7 (Figure 1) in the model reaction (Table 2) working at $100{ }^{\circ} \mathrm{C}$ under $\mu \mathrm{W}$ irradiation. Organocatalysts 2-5 (entries 2-7) of $R$ configurations led to the formation of products $(1 S, 3 S)-\mathbf{1 1} \mathbf{b}$ and $(1 S, 3 R)-\mathbf{1 2} \mathbf{b}$, unlike amine $(S)-1$ (entry 1 ) which promoted the production of succinimides $(1 R, 3 R)-\mathbf{1 1 b}$ and $(1 R, 3 S)-\mathbf{1 2 b}$ of opposite configurations.

The latter, unlike Carter's results with different electrophiles, ${ }^{11}$ proved to be the best compromise in this transformation in terms of yields (79\%), diastereomeric ratio (75/25) and especially enantiomeric excess for major diastereomer $\mathbf{1 1 b}$ (87\%), 1.5 times higher than that obtained by the best of its competitors 3 (entry 3 ). Lower yields (0-50\%) were observed with dual catalysts 5-7 (entries 5-10) incorporating both an amine and an acid function. In particular, Carter's catalyst $\mathbf{5}$ (entry 5), used in the absence of co-catalyst $\mathbf{8 c}$, led to the production of products $\mathbf{1 1 b}$ and $\mathbf{1 2 b}$

Table 2. Screening the effect of various amines as organocatalysts.

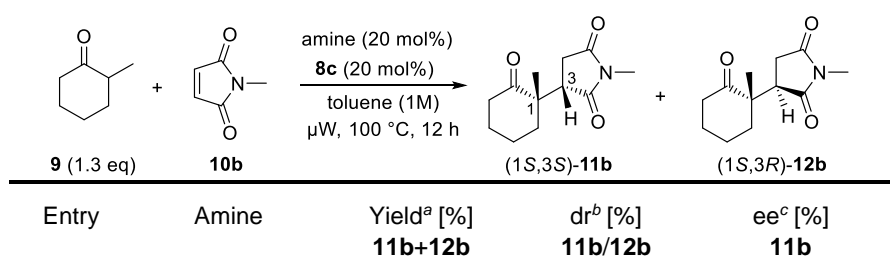




\begin{tabular}{ccccc}
\hline 1 & $(S)-\mathbf{1}^{d}$ & 79 & $75 / 25$ & 87 \\
2 & $(R)-\mathbf{2}$ & 82 & $78 / 22$ & 48 \\
3 & $\mathbf{3}$ & 64 & $70 / 30$ & 56 \\
4 & $\mathbf{4}$ & 62 & $70 / 30$ & 30 \\
5 & $\mathbf{5}^{e}$ & 25 & nd & nd \\
6 & $\mathbf{5}$ & 50 & $97 / 3$ & nd \\
7 & $\mathbf{5}^{e, f}$ & 0 & - & - \\
8 & $\mathbf{6}^{e}$ & 0 & - & - \\
9 & $\mathbf{6}$ & 24 & $79 / 21$ & 0 \\
10 & $\mathbf{7}$ & 47 & $97 / 3$ & nd
\end{tabular}

${ }^{a}$ Combined yield of $\mathbf{1 1} \mathbf{b}$ and $\mathbf{1 2} \mathbf{b}$ isolated by flash chromatography. ${ }^{b}$ Determined by ${ }^{1} \mathrm{H}$ NMR. ${ }^{c}$ Determined by chiral HPLC. ${ }^{d}(S)-1$ catalyzed the formation of opposite enantiomers $(1 R, 3 R)-\mathbf{1 1} \mathbf{b} / \mathbf{1 2} \mathbf{b}$. ${ }^{e}$ Reaction without co-catalyst $\mathbf{8 c} .^{f} \mathrm{At}$ toluene reflux for $24 \mathrm{~h}$.

in only $25 \%$ yield, while the same reaction carried out without $\mu \mathrm{W}$ irradiation (entry 7 ) led to no transformation of starting materials.

Scope of the reaction of cyclohexanone 9 with respect to the maleimide was studied as shown in Table 3, following the optimized reaction conditions. In these reactions, $4-10 \%$ of undesired regioisomers (Scheme 1) were detected by ${ }^{1} \mathrm{H}$ NMR analysis and $4-15 \%$ of aza-Michael adducts 13 were isolated. Whatever the nature of the $\mathrm{N}$-substituents of maleimides $\mathrm{R}$, the desired products $\mathbf{1 1}$ and corresponding diastereomers $\mathbf{1 2}$ were all obtained in good yields (67-79\%), diastereomeric ratio (up to 95/5) and high to excellent enantioselectivities for 11 (91-99\% ee).

Table 3. Scope of reaction of $\mathbf{9}$ with respect to the maleimide. ${ }^{a}$

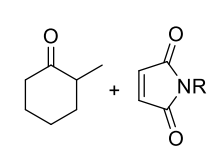

$9(1.3 \mathrm{eq}) \quad 10$

\begin{tabular}{|c|c|c|c|c|}
\hline Entry & Maleimide $(\mathrm{R})$ & $\begin{array}{c}\text { Yield }^{b}[\%] \\
11+12\end{array}$ & $\begin{array}{l}\mathrm{dr}^{c}[\%] \\
11 / 12\end{array}$ & $\begin{array}{c}\mathrm{ee}^{d}[\%] \\
(1 R, 3 R)-11\end{array}$ \\
\hline 1 & $10 a(H)$ & 70 & $>95 / 5$ & 99 \\
\hline 2 & 10b (Me) & 79 & $82 / 18$ & 92 \\
\hline 3 & 10e (cyclohexyl) & 77 & nd & 93 \\
\hline 4 & $10 f(\mathrm{Ph})$ & 67 & nd & 98 \\
\hline 5 & $10 \mathbf{i}\left(4 \mathrm{FC}_{6} \mathrm{H}_{4}\right)$ & 70 & nd & 91 \\
\hline
\end{tabular}

a $4-10 \%$ of regioisomers (Scheme 1 ) were detected by ${ }^{1} \mathrm{H}$ NMR and $4-15 \%$ of aza-Michael adducts $\mathbf{1 3}$ were isolated. ${ }^{b}$ Combined yields of $\mathbf{1 1}$ and $\mathbf{1 2}$ isolated by flash chromatography. ${ }^{c}$ Determined by ${ }^{1} \mathrm{H}$ NMR. ${ }^{d}$ Determined by chiral HPLC.

The substrate scope was further evaluated by studying Michael reaction between $\alpha$-methylcyclopentanone (14) and various maleimides 10 (Table 4), using either (S)-1 or $(R)-\mathbf{1}$, in the presence of co-acid $8 \mathrm{c}$ (20 mol\% each). As a consequence, depending of the antipodal amine used, either $(1 R, 3 R)-\mathbf{1 5}$ or its antipode were obtained as the major enantiomer. For simplification purposes, results are presented for amine (S)-1. In this series, a minor quantity of aza-Michael adducts $\mathbf{1 3}$ and regioisomers were detected by ${ }^{1} \mathrm{H}$ NMR analysis of the crude reaction mixtures. Pure samples were isolated for analysis purposes. The electronic nature of the $\mathrm{R}$ groups of maleimide, from donor (entries 2-5) to attractor (entries 6-12) as well as that of their respective larger or smaller sizes did not significantly influence products distribution in these reactions, giving good yields (58-71\%), good to excellent diastereoselectivities $(67 / 33$ to $98 / 2)$ and enantioselectivities for compounds 15 (75-98\% ee).

Table 4. Scope of reaction of $\alpha$-methyl cyclopentanone 14 with respect to the maleimide. ${ }^{a}$

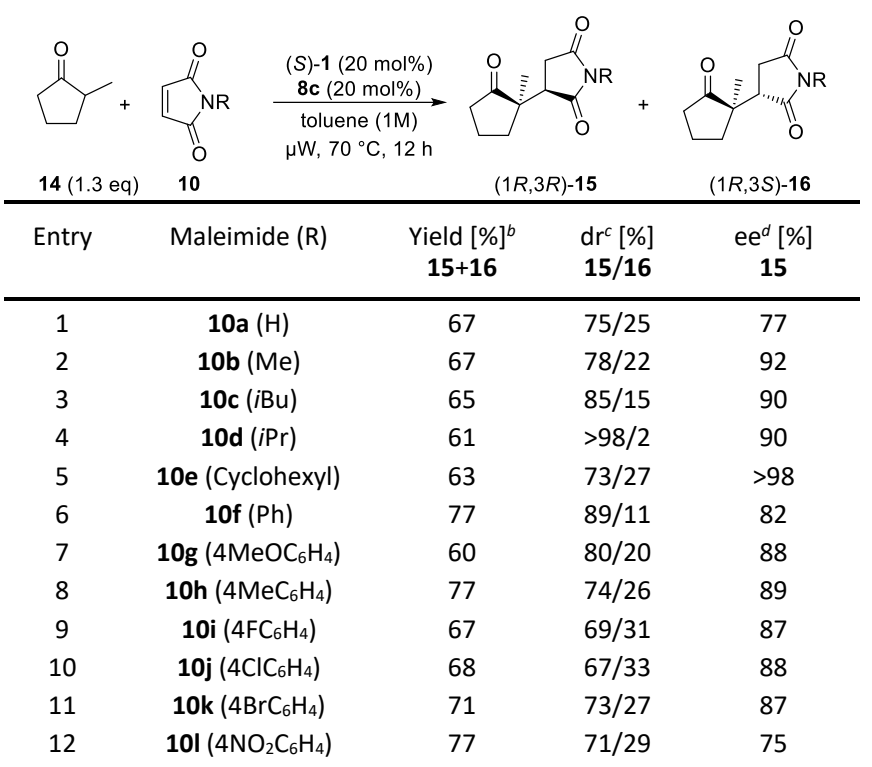

${ }^{a}$ Minor quantities of aza-Michael adducts 13 and regioisomers were detected by ${ }^{1} \mathrm{H}$ NMR of the crude reaction mixtures. ${ }^{b}$ Combined yields of $\mathbf{1 5}$ and $\mathbf{1 6}$ isolated by flash chromatography. ${ }^{c}$ Determined by ${ }^{1} \mathrm{H}$ NMR. ${ }^{d}$ Determined by chiral HPLC.

We propose the following mechanism (Scheme 2) to explain the influence of a co-acid on the reaction process. Without acidic assistance, aza-Michael addition of the primary amine catalyst on the maleimides would be favored delivering quantitatively aza-Michael adducts 13.

In the presence of an acid, formation of imines $\mathbf{1 7}$ would predominate and deliver, via an equilibrium, the reactive Michael donor (thermodynamic) enamines $\mathbf{1 8 a}$ prone to react with the maleimides 10 . The resulting imines 19 would then be hydrolysed to generate major diastereomers $\left(1 R^{*}, 3 R^{*}\right)-\mathbf{1 1}(\mathrm{n}=$ $1)$ or $\left(1 R^{*}, 3 R^{*}\right)-\mathbf{1 5}(\mathrm{n}=2)$ bearing a quaternary-tertiary carbon stereocenters sequence, along with minor amount of the corresponding diastereoisomers $\left(1 R^{*}, 3 S^{*}\right)-11(\mathrm{n}=1)$ or $\left(1 R^{*}, 3 S^{*}\right)-15(\mathrm{n}=2)$ resulting from a compact exo approach. This mechanism and the stereochemical outcome of this reaction are based on previous studies implying stoichiometric addition of transient enamines on different Michael acceptors. ${ }^{10,20}$ The preference for the formation of diastereomers $\mathbf{1 1}$ and $\mathbf{1 5}$ was thus explained (for a detailed discussion, see the electronic supporting information) according to our empirical model and related experimental and theoretical ${ }^{20}$ studies, arising from a syn compact approach of the enamine 18a by the electrophiles 10 in an endo orientation delivering imines 19. Diastereoisomers $\left(1 R^{*}, 3 S^{*}\right)-\mathbf{1 1}(\mathrm{n}=1)$ or $\left(1 R^{*}, 3 S^{*}\right)-15(\mathrm{n}=2)$ result from a syn compact approach of $18 \mathrm{a}$ by 10 in an exo orientation. 


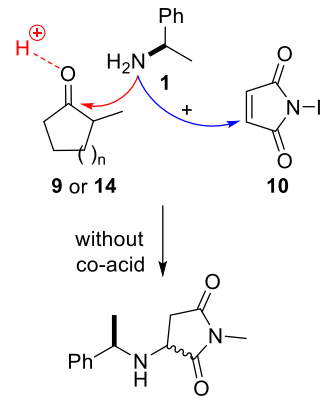

13

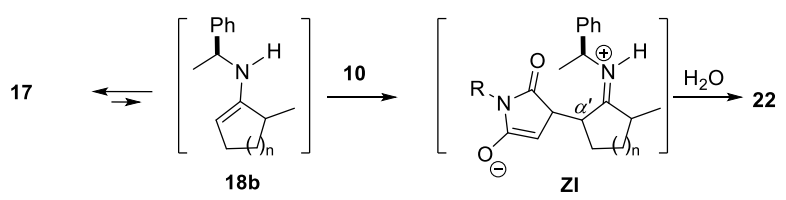

Scheme 2. Proposed mechanism explaining the influence of co-acid on the course of the reaction and the preferred $\alpha$-alkylation of enamines $18 \mathrm{a}$.

This favored stereochemical outcome was further confirmed by an X-ray diffraction analysis of the major maleimide adduct $(1 S, 3 S)$-15b (Figure 2 ) issued from the reaction performed with the antipodal amine $(R)-\mathbf{1}$, all other parameters being unchanged, as described in table 4.
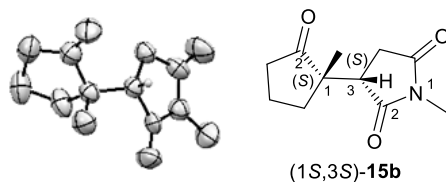

Figure 2. Thermal ellipsoid plot (left) of the molecular structure of (3S)-1-methyl-3-[(1S)1-methyl-2-oxocyclopentyl]-2,5-pyrrolidinedione 15b (right). Most of the $\mathrm{H}$ atoms have been omitted for clarity. The ellipsoids enclose $50 \%$ of the electronic density.

This organocatalytic process is driven by the concerted (but non synchronous) $\mathrm{C}-\mathrm{C}$ bond creation and $\mathrm{H}$-transfer from the nitrogen atom of the transient enamine to the $\alpha$-carbon atom of the electrophile 10 (18a $\rightarrow$ 19). The endo compact concerted pathway leading to the quaternary adduct 19 has lower activation energy than the pathway leading to a zwitterionic intermediate (ZI, scheme 2 ) delivering after prototropy the $\alpha^{\prime}$ regioisomers 22, although the loose anti approach of the tertiary enamine $\mathbf{1 8 b}$ by the electrophile $\mathbf{1 0}$ is lower in energy than the more hindered compact one implying enamine $\mathbf{1 8 a}$ (Curtin Hammett like mechanism and steric control).

Also, when pure quaternary adducts $\mathbf{1 5 f}$ and its corresponding minor diastereomer $\mathbf{1 6 f}$ were separately reacted in the presence of primary amine $\mathbf{1}$ under the reaction conditions used in that reaction, no transformation in mixtures of diastereomers 15f/16f were observed excluding the possibility of a thermodynamic control in our case (see ESI page S114) and possible isomerization. ${ }^{21}$

Inspired by asymmetric Michael atroposelective desymmetrization of maleimides reported by Bencivenni et al., ${ }^{20}$ atropoisomers $(M, 1 R, 3 R)-\mathbf{1 5 m a}$ and $(P, 1 R, 3 R)-\mathbf{1 5 m b}$ incorporating three stereogenic elements were isolated in fair yields and enantioselectivity (Figure 3) upon reaction of maleimide $10 \mathrm{~m}$

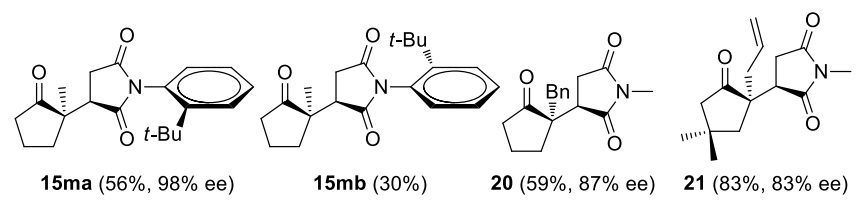

Figure 3. Exploration of the substrate scope with respect to maleimide and cyclopentanone. Reaction conditions: (S)-1 (20 mol\%), 8c (20 mol\%), $70^{\circ} \mathrm{C}, \mu \mathrm{W}, 12 \mathrm{~h}$.

More sterically hindered structures as products $\mathbf{2 0}$ and $\mathbf{2 1}$ were also synthesized through reaction of maleimide $10 \mathrm{~b}$ with the corresponding cyclopentanones in 59 and $83 \%$ yield, respectively, $87 \%$ and $83 \%$ ee's. Notably, potential diastereomers and regioisomers were not obtained in these transformations.

\section{Conclusions}

To conclude, we have developed an unprecedented organocatalyzed pathway to succinimide derivatives bearing a quaternary-tertiary carbon stereocenters sequence via a Michael process involving unactivated $\alpha$-alkyl cyclic ketones and $b$-substituted electrophiles under microwave-assisted conditions. The catalytic system used, composed of unchanged chiral primary amine and co-carboxylic acid both commercially available at low cost, has made it possible to perform this crowded Michael reaction. It promotes a fourfold control, including chemoselectivity through the addition of carboxylic acid co-catalyst ( $C$ vs $N$ Michael addition), regioselectivity at the more substituted $\alpha$-position, as well as diastereo- and enantioselectivity in good yields, enantio- and diastereoselective excesses given the high steric hindrance generated in the desired succinimides exhibiting a sequence of adjacent stereogenic quaternary and tertiary carbon centers. This methodology paves the way to an easy access to chiralsubstituted compounds of interest owing to the occurrence of the succinimide moiety in natural products and some clinical drugs. ${ }^{18}$ Synthetic applications and extension of this methodology to other cycloalkyl ketones and other bsubstituted electrophiles will be published in due course.

\section{Conflicts of interest}

There are no conflicts to declare.

\section{Acknowledgements}

Authors are thankful to BioCIS, University Paris-Sud, Centre National de la Recherche Scientifique (CNRS), Université ParisSaclay (France) \& LabEx LERMIT (ANR-10-LABX-33) for their financial support during the time devoted to this contribution. 
Camille Dejean (NMR department) and Karine Leblanc (HPLC, BioCIS) are warmly acknowledged.

\section{Notes and references}

‡ Electronic supplementary information (ESI) available: Experimental procedures and characterization of the Michael and aza-Michael addition products. CCDC 1847461 contains the supplementary crystallographic data for this paper. These data are provided free of charge by The Cambridge Crystallographic Data Centre. For ESI and crystallographic data in CIF or other electronic format see DOI: XXXXX

1 K. W. Quasdorf, L. E. Overman, Nature 2014, 516, 181; X.-P. Zeng, Z.Y. Cao, Y.-H. Wang, F. Zhou, J. Zhou, Chem. Rev. 2016, 116, 7330.

2 (a) G. Pandey, A. Mishra, J. Khamrai, Tetrahedron 2018, 74, 4903; (b) L. M. Repka, S. E. Reisman, J. Org. Chem. 2013, 78, 12314.

3 (a) E. Reyes, U. Uria, J. L. Vicario, L. Carrillo, Org. React. 2009, 121, 5811; (b) J. Christoffers, A. Baro, Angew. Chem. Int. Ed. 2003, 42, 1688.

4 (a) J. Alemán, A. Parra, H. Jiang, K. A. Jørgensen, Chem. Eur. J. 2011, 17, 6890; O. V. Serdyuk, C. M. Heckel, S. B. Tsogoeva, Org. Biomol. Chem. 2013, 11, 7051; (b) G. Koutoulogenis, N. Kaplaneris, C. G. Kokotos, Beil. J. Org. Chem. 2016, 12, 462.

5 M. P. Lalonde, Y. Chen, E. N. Jacobsen, Angew. Chem. Int. Ed. 2006, 45, 6366.

6 X. Wang, M. Kitamura, K. Maruoka, J. Am. Chem. Soc. 2007, 129, 1038.

7 (a) G. Bartoli, M. Bosco, A. Carlone, A. Cavalli, M. Locatelli, A. Mazzanti, P. Ricci, L. Sambri, P. Melchiorre, Angew. Chem. Int. Ed. 2006, 45, 4966 ; (b) A. Luridiana, A. Frongia, D. J. Aitken, R. Guillot, G. Sarais, F. Secci, Org. Biomol. Chem., 2016, 14, 3394.

8 (a) R. Cano, A. Zakarian, G. P. McGlacken, Angew. Chem. Int. Ed. 2017, 56, 9278; (b) I. Urruzuno, O. Mugica, M. Oiarbide, C. Palomo, Angew. Chem. Int. Ed. 2017, 56, 2059.

9 M. Pfau, G. Revial, A. Guingant, J. d'Angelo, J. Am. Chem. Soc. 1985, 107, 273.

10 Review: (a) J. d'Angelo, D. Desmaële, F. Dumas, A. Guingant, Tetrahedron: Asymmetry 1992, 3, 459; See for example: (b) I. Jabin, G. Revial, A. Tomas, P. Lemoine, M. Pfau, Tetrahedron: Asymmetry 1995, 6, 1795; (c) C. Cavé, D. Desmaële, J. d’Angelo, C. Riche, A Chiaroni, J. Org. Chem. 1996, 61, 4361; (d) C. Cavé, A. Gassama, J. Mahuteau, J. d'Angelo, C. Riche Tetrahedron Lett. 1997 38, 4773; (e) C. Thominiaux, S. Roussé, D. Desmaële, J. d'Angelo, C. Riche, Tetrahedron: Asymmetry 1999 10, 2015; (f) C. Camara, D. Joseph, F. Dumas, J. d'Angelo, A. Chiaroni, Tetrahedron Lett. 2002, 43, 1445; (g) L. Keller, F. Dumas, J. d'Angelo; Eur. J. Org. Chem. 2003, 2488; (h) C. Camara, L. Keller, F. Dumas, Tetrahedron: Asymmetry 2003, 14, 3263; (i) H. Krawczyk, M. Śliwiński, J. Kędzia, J. Wojciechowski, W. M. Wolf, Tetrahedron: Asymmetry 2007, 18, 2712; (j) Y. Guo, Q. Liu, Y. Jia, Chem. Commun., 2015, 51, 889; (k) X. Yao, X. Shan, L. Zu, Org. Lett. 2018 20, 6498.

11 (a) J. Y. Kang, R. G. Carter, Org. Lett. 2012, 14, 3178; (b) J. Y. Kang, R. C. Johnston, K. M. Snyder, P. H.-Y. Cheong, R. G. Carter, J. Org. Chem 2016, 81, 3629.

12 R. Horinouchi, K. Kamei, R. Watanabe, N. Hieda, N. Tatsumi, K. Nakano, Y. Ichikawa, H. Kotsuki, Eur. J. Org. Chem. 2015, 2015, 4457.

13 I. Felker, G. Pupo, P. Kraft, B. List, Angew. Chem. Int. Ed. 2015, 54, 1960.

14 X. Yang, F. D. Toste, Chem. Sci. 2016, 7, 2653.

15 (a) M. Kousara, A. Ferry, F. Le Bideau, K. L. Serré, I. Chataigner, E. Morvan, J. Dubois, M. Chéron, F. Dumas, Chem. Commun. 2015, 51, 3458; (b) M. Kousara, F. Le Bideau, R. Ibrahim, A. Ferry, P. E. Venot, C. Dejean, J. Raingeaud, J. Dubois, P. Retailleau, F. Dumas, Synthesis 2016, 48, 1637.

16 F. Le Bideau, M. Kousara, L. Chen, L. Wei, F. Dumas, Chem. Rev. 2017, 117, 6110.

17 (a) F. Yu, X. Sun, Z. Jin, S. Wen, X. Liang, J. Ye, Chem. Commun., 2010, 46, 4589; (b) T. C. Nugent, A. Sadiq, A. Bibi, T. Heine, L. L. Zeonjuk,
N. Vankova, B. S. Bassil, Chem. Eur. J. 2012, 18, 4088; (c) M. D. Díazde-Villegas, J. A. Gálvez, R. Badorrey, P. López-Ram-de-Víu, Adv. Synth. Catal. 2014, 356, 3261; (d) J. Li, S. Qiu, X. Ye, B. Zhu, H. Liu, Z. Jiang, J. Org. Chem. 2016, 81, 11916; (e) S. Liu, K. Maruoka, S. Shirakawa, Angew. Chem. Int. Ed. 2017, 56, 4819.

18 (a) R.S. Vardanyan, V.J. Hruby, in Synthesis of Essential Drugs, 2006, pp 125-133; (b) P. Chauhan, J. Kaur, S. S. Chimni, Chem. Asian J. 2013, 8, 328; (c) T. Honda, I. Ojima, in Modern Synthesis Processes and Reactivity of Fluorinated Compounds, 2017, pp 499-531.

19 L. Vandromme, L. Chen, L. Wei, F. Le Bideau, A. Loupy, P. Lesot, O. Lafon, E. Tran Huu Dau, P. Chaminade, F. Dumas, MOL2NET, International Conference on Multidisciplinary Sciences, 2015, 1, 1 (doi:10.3390/MOL2NET-1-a003).

20 (a) A. Sevin, J. Tortajada, M. Pfau, J. Org. Chem. 1986, 51, 2671 (b) M. E. Tran Huu Dau, C. Riche, F. Dumas, J. d'Angelo, Tetrahedron: Asymmetry 1998, 9, 1059; (c) M. J. Lucero, K. N. Houk, J. Am. Chem. Soc. 1997, 119, 826.

21 M. Pizzonero, F. Hendra, S. Delarue-Cochin, M.-E. Tran Huu-Dau, F. Dumas, C. Cavé, M. Nour, J. d'Angelo Tetrahedron: Asymmetry, 2005, 16, 3853.

22 N. Di lorio, F. Champavert, A. Erice, P. Righi, A. Mazzanti, G. Bencivenni, Tetrahedron 2016, 72, 5191. 